\title{
Yapay Zeka'nın Kültür ve Sanatla Olan İlişkisi
}

\author{
Yusuf Uzun $^{1 *}$, Beyzanur Akkuzu², Mehmet Kayrıc1 ${ }^{3}$ \\ 1* Necmettin Erbakan Üniversitesi, Seydişehir Ahmet Cengiz Mühendislik Fakültesi, Bilgisayar Mühendisliği Bölümü, Konya, Türkiye, (ORCID: 0000-0002-7061- \\ 8784),yuzun@erbakan.edu.tr \\ ${ }^{2}$ Necmettin Erbakan Üniversitesi, Seydişehir Ahmet Cengiz Mühendislik Fakültesi, Bilgisayar Mühendisliği Bölümü, Konya, Türkiye, (ORCID: 0000-0001-6435- \\ 3874),beyzaakkuzu@gmail.com \\ ${ }^{3}$ Necmettin Erbakan Üniversitesi, Seydişehir Ahmet Cengiz Mühendislik Fakültesi, Makine Mühendisliği Bölümü, Konya, Türkiye, (ORCID: 0000-0003-1178-5168), \\ yuzun@erbakan.edu.tr
}

(1st International Conference on Applied Engineering and Natural Sciences ICAENS 2021, November 1-3, 2021)

(DOI: 10.31590/ejosat.1010691)

ATIF/REFERENCE: Uzun, Y., Akkuzu, B. \& Kayrıı, M (2021). Yapay Zeka'nın Kültür ve Sanatla Olan İlişkisi. Avrupa Bilim ve Teknoloji Dergisi, (28), 753-757.

\section{$\ddot{\mathbf{O} z}$}

Toplumun yaşamını sürdürebilmesi için gerekli olan ihtiyaçlarla beraber teknoloji ve sanat da gelişmeye başlamıştır. İnsanların yüzyıllar boyunca geçirmiş oldukları evrimler, yaşam biçimleri ve fikrî akımları ile sanata bakış açılarında da yenilikler meydana gelmiş̧tir. Yapay zekâ ve sanat genel olarak yaşama, uygarlıkların düşünce dünyasının gelişmesine ve sanatsal yaratıya kazandırılacak yeni bakış açılarıyla yaklaşmayı gerektirmektedir. Teknolojinin getirdiği yeniliklerle birlikte gelişen yeni sanat anlayışı ve insan gibi düşünen sistemler yaratma fikri ile gelişen yapay zekâ, algoritmalar ve yapay sinir ağları ile birçok sanat çalışması üretmiştir. Sophia, Deniz Yılmaz, GAN, AICAN, AARON gibi birçok yapay zekâ çalışmaları mevcuttur ve hepsinin çalışma prensipleri kendilerine özgüdür. Yapay zekanın asıl amacı makinenin bu süreci işleyişi ve makinenin yaratıcılığını geliştirmeye odaklanmaktadır. Tabi bununla beraber yapay zekanın ürettiği çalışmaların insan taklidi olarak düşünülmesi ve sanatı tam olarak yansıtmadığı fikri ile yapay zekanın ürettiği çalışmaların eser olarak sayılıp sayılmayacağı ve yapay zekanın insanın önüne geçip geçmeyeceği yönünde de birçok tartışma söz konusudur.

Anahtar Kelimeler: Sanat, Toplum, Teknoloji, Yapay Zeka.

\section{The Relationshıp of Artificial Intelligence to Culture and Art}

\begin{abstract}
Technology and art have started to develop along with the needs necessary for the society to survive. There have also been innovations in the evolutions, lifestyles and intellectual movements that people have undergone over the centuries, and in their perspectives on art. Artificial intelligence and art generally require approaching life, the development of civilizations' world of thought, and artistic creation with new perspectives. He has produced many works of art with artificial intelligence, algorithms and artificial neural networks that have developed with the idea of creating systems that think like human and the new understanding of art that develops with the innovations brought by technology. There are many artificial intelligence studies such as Sophia, Deniz Y1lmaz, GAN, AICAN, AARON and their working principles are unique to them. The main purpose of artificial intelligence focuses on the functioning of this process of the machine and improving the creativity of the machine. Of course, with the idea that the works produced by artificial intelligence are considered as human imitations and do not fully reflect the art, there are many debates about whether the works produced by artificial intelligence can be counted as works and whether artificial intelligence will overtake humans.
\end{abstract}

Keywords: Art, Society, Technology, Artificial Intelligence.

\footnotetext{
* Sorumlu Yazar: yuzun@erbakan.edu.tr
} 


\section{Giriş}

İnsanoğlunun yaşamını devam ettirebilmesi için gerekli olan temel gereksinim ihtiyacı üretim biçimidir. Üretim biçiminde kullanılan üretim güçleri (insan, makine gücü, ham madde, alet vb.) toplumun birbirleriyle olan iletişimini de belirlemiştir (Kozlu, 2009). Üretim ile başlayan bilim ve sanat birçok alanda gelişim göstermiştir. Platon ve Aristoteles'e göre sanatın nasıl oluştuğu yönündeki "yansıtmacı" anlayış 20. yüzyılın ortalarına kadar yeni görünümlerle ana ilke haline gelmiştir. İnsanların yaşamları boyunca geçirmiş oldukları evrimler, yaşam biçimleri ve sanata bakış açıları farklı görünümlerle gelişimini sürdürmüş ve teknolojinin getirdiği yeniliklerle birlikte gerçekliği işleme biçimini de geliştirmiştir (Artut,2019).

Teknolojik gelişmeler günümüz sanat alanında yeni teoriler geliştirme olgusuyla yapay zekâ, bugün fikrî ürünler meydana getirebilir hale gelmiştir (Gözübüyük ve Ball1,2020). Yapay zekâ biliminin temelini insan zekâsı konu almaktadır. Bu açıdan yapay zekanın insan zekasını taklit etmesiyle bilişsel faaliyetlerin bilgisayarlar tarafından yapılabilir hale geldiği görülmektedir. Sanat alanında yapılan faaliyetlerde sanatçılar her ne kadar bir sanat eseri oluşturabilmek için kurgusal, imgesel bir dil kullanmak zorundaysa yapay zekada algoritmaları ve yapay sinir ağlarını birleştirerek kendini geliştirmek durumundadır (Akbulut,2020).

Hanson Robotics tarafından geliştirilen "insana en çok benzeyen robot" unvanına sahip olan Sophia'nın birçok özelliği bulunmaktadır. Bilimsel ve sanatsal yönden de geliştirilmiş olan Sophia, yaptığı tablolar ile bir robotunda bir sanat eseri ortaya çıkarabileceğini göstermiştir (Şekil 1).

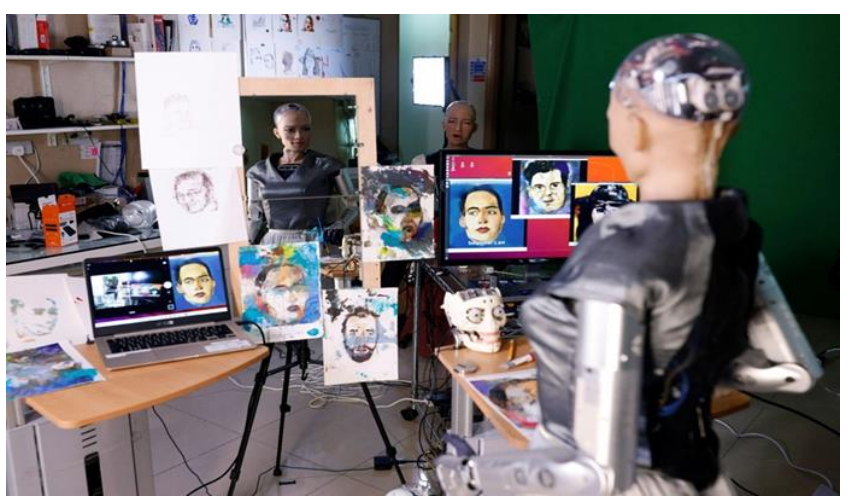

Şekil 1 Robot Sophia ve Yaptığı Çalışmalar (Resim 1)

Teknolojide yaşanan gelişmelerin hızı düşünüldüğünde sanat alanında yapılan çalışmalara yenileri eklenerek bu çalışmaların giderek artacağını söylemek mümkündür (Gözübüyük, 2021). Müzik, roman, şiir ve senaryo yazmak gibi birçok alanda da yapay zekâ kendini göstermiştir (Ballı, 2020).

\section{GAN ve CAN'ın Çalışma Mantığı}

Sanatın bir makineye nasıl öğretildiğini anlamak için GAN (Generative Adversarial Network) ve CAN (Creative Adversarial Network) olarak adlandırılan yapay zekâ algoritmalarını incelemek iyi olacaktır. GAN'da iki tane yapay sinir ağ mevcuttur ve ikisinin de amaçları farklıdır. İlki sahte veri üretmeye çalışmaktadır, diğeri ise sinir ağının ürettiği veri ile gerçek veriyi karşılaştırıp üretilen ürünün sahte olup olmadığını ayırt etmeye çalışmaktadır. Ayırt edebilen sinir ağ 1 insan tarafından çizilmiş resimleri görebilen ve üreticiden aldığ resimlerle gerçek resmi kıyaslayarak farklılıkları listelemektedir. Geri bildirimler alarak çizimler düzeltilebiliyor ve tekrar tekrar bir karşılaştırma yapılmaktadır. Bu sayede insanın ürettiği sanat eserine benzer resimler elde etmiş oluyor. Ancak GAN insanı daha çok taklit ettiği düşüncesiyle çok fazla tercih edilmemektedir (Ünal, 2018).

CAN'da ise makine, iki farklı durum arasında eğitilir. Birinde makineye gösterilen sanatın estetiğini takip eder sanat dağılımından sapmayı en aza indirmek için, diğerinde ise önceden oluşmuş olan bir stili taklit ederse makine cezalandırılır ve bu sayede stil belirsizliği en üst düzeye çıkarılmış olur. CAN tarafından çizilmiş ve en çok beğenilen tablolar Şekil 2'de görülmektedir [Mazzone ve Elgammal, 2019 ).
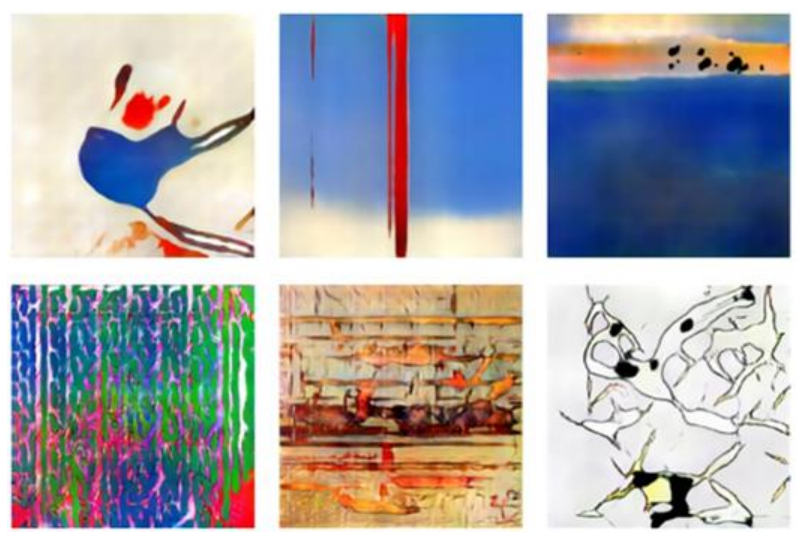

Şekil 1 AICAN Tarafından Yapılan Çalışmalar (AICAN)

CAN'ın oluşmasındaki asıl amaç mevcut akımlardan kopmadan ve onları olduğu gibi taklit etmeden yeni bir sanatsal çalışma ortaya çıkarmaktır. CAN'ın gelişiminde yaklaşık 80.000'den fazla resim kullanılmıştır. Resimlerin hangi akımlara ait oldukları ise (empresyonist, kübist vs.) işaretlenerek ayırt edici sinir ağında eğitilmiştir. GAN'da ki gibi üretici sinir ağı ile yeni çizimler elde edildi ve geri bildirimlere göre çizimlerini değiştirdi. CAN'ın GAN'dan farklı olarak hedefi yapılan stillerden farklı çalışmalar üretmek ve ana sanat akımlarının da dışına çıkmamak. Şekil 3'de, jeneratörün, biri sanatın stil sınıflarından sapmalarını ölçen, diğerinde stil belirsizliğini ölçen iki sinyal alan CAN ağının bir blok diyagramı verilmiştir. 


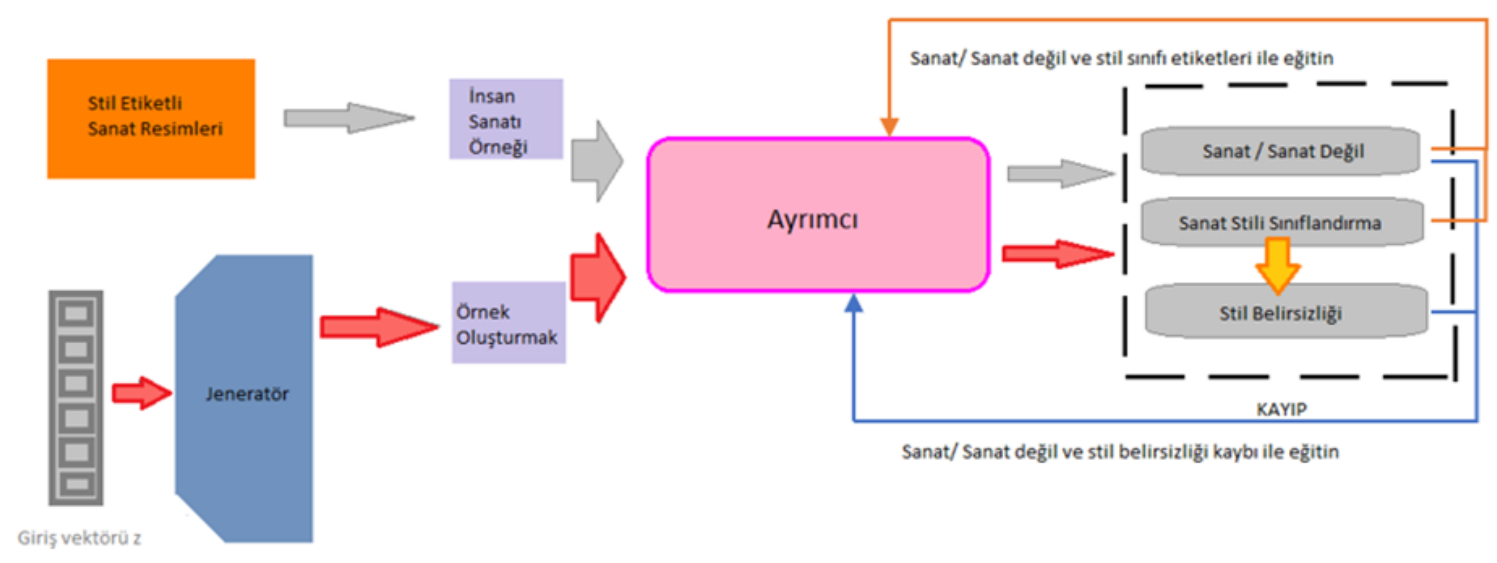

Şekil 2 Ahmed Elgammal Tarafından Oluşturulan CAN Çalışma Mantığı Blok Şeması (Mazzone ve Elgammal, 2019)

\section{Yapay Zekâ Tarafından Üretilen Sanat Çalışmaları}

1956 y1lında John McCarthy tarafından "insan gibi düşünen” sistemler yaratma fikri ile "yapay zekâ" kavramı ortaya çıktı (Ünal, 2018). McCarty yapay zekay1, "zeki makineler ve bilgisayar programları yapma bilimi” şeklinde tanımlamıştır (Gözübüyük, 2021). O günden bugüne kadar birçok bilim adamını ve araştırmacıyı kendine çekmeyi başarmıştır.

Yapay zekayı üç başlık altında kategorize edebilmek mümkündür: Bir amaç için özelleşmiş yapay zekâ (Sınırlı YZ), öğretilenler ile birlikte çok sayıda görevi yerine getirebilen ve insana özgü kabiliyetlere sahip (güçlü) yapay zekâ (Genel YZ), insan zekasından üstün ve en yetenekli insan zekasından daha gelişmiş yapay zekâ (Süper YZ) olarak sınıflara ayrılabilir [Artut, Ünal]. İnsan gibi davranabilme yeteneğine sahip güçlü yapay zekaya halen uzağız. Ancak günümüzde sınırlı yapay zekâ uygulamaları bile bizi birçok alanda geçebilecek hale geldi. Örneğin Google mühendislerinden Alexander Mordvintsev tarafindan geliştirilen Deep Dream'in amac1; insan gibi düşünebilmek ve karmaşık örüntülerden yeni eserler üretebilen bir sistem (Aslan, 2019). Deep Dream, resimlerde ne gördüğünü ayırt etmek üzere eğitilmiş olan derin sinir ağları ile resimde ne görüldüğünden çok "neye daha çok benziyorsa ona benzet" mantığı ile çalışmaktadır. Yani bunu bizim günlük hayatımızda bulutlara bakıp da onları bir şeylere benzetmemiz gibi düşünülebilir. Google'ın derin sinir ağları da daha çok neleri ayırt etmek için eğitildi ise (genelde hayvan görselleri) kendilerine gösterilen resimleri de onlara benzetmeye çalışmaktadır (Şekil 4).

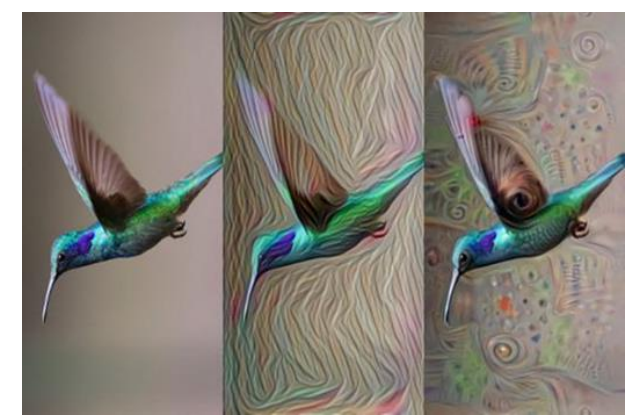

Şekil 4. Deep Dream “Soyut Sanatın Yeni Bir Biçimi” (Dijital Bask1)
Bir diğer sanat alanı olan müzik alanında da yapay zekanın etkileri görülmektedir. Minimum insan müdahalesi ile müzik yaratma fikri Antik Yunan'dan beridir çeşitli yöntemlerle geliştirilmeye çalışılmıştır. Plato, Pisagor, John Cage, Lejaren Hiller ve daha birçok isim bu çalışmalara katkıları olan kişiler olarak sayılabilir. Son yıllarda ise bu işi yapay zekâ devralmış gözüküyor.

Eşsiz besteleri ve armonideki teknik yetkinlikleri ile barok müziğinin önde gelen isimlerinden olan Johann Sebastian Bach'ın 300'den fazla polifonik ilahi bestesi vardır. Bach'ın kendine has geliştirdiği mantıksal yapı, yıllardır araştırmacıların ilgisini çekmiştir. Sony Bilgisayar Laboratuvarında yapılan bir çalışmada Bach'ın besteleri DeepBach adını verdikleri algoritmanın eğitim ve test işlemlerinde kullanılmıştır. Algoritmanın görevi; Bach'ın eserlerinde kullandığı soprano melodileri algoritmaya verildiğinde Bach tarzında armoniler oluşturmaktı. Bu çalışmanın sonucunda 1200 'den fazla katılımcıdan oluşmaktadır. $\mathrm{Bu}$ katılımcıların $\% 25$ 'i profesyonel müzisyen ve müzik öğrencilerinden oluşan bir dinleti gerçekleştirilmiştir. $\mathrm{Bu}$ dinletide dinledikleri bestenin Bach'a mı yoksa bilgisayar kurgusu mu olduğunu düşündükleri soruldu. Farklı yapay zekâ algoritmalarının da ürettiği besteler ile bir karşılaştırma yapıldı ve katılımcıların çoğu DeepBach'ın ürettiği besteleri, Bach'ın besteleri sandı ve en yüksek puanı DeepBach aldı (Şekil 5) (Ünal, 2018).

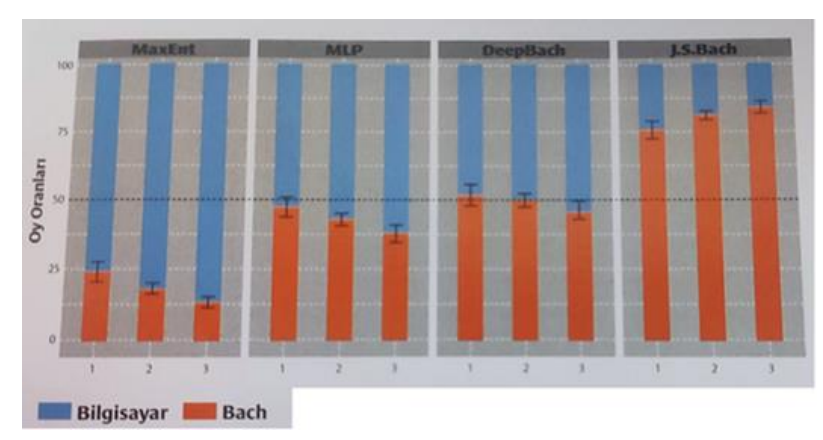

Şekil 5. "Bach mı Bilgisayar Mı?” 1: Hobi olarak müzik dinleyenler, 2: Amatör müzisyenleri, 3: Öğrenciler ve Profesyonel Müzisyenler (Ünal, 2018) 
Yapay Zekâ, mantık, ak1l yürütme, problem çözme ve yaratıcılık gibi yeteneklerin tümünün bilişim bir sistemi tarafindan yerine getirilebilmesidir. Bahsedilen yeteneklerin başarabilmesi için mantık, olasılık, istatistik gibi matematik öğeleri kullanılmaktayken bir yandan da algılama, yorumlama, öğrenme gibi bilişsel disiplinlerden de faydalanılmaktadır.

Bilişsel disiplinlerin kullanıldığı ve sanatın bir farklı mecrası olan edebiyat alanında da yapay zekâ başarılı bir çalışmaya imza atmıştır. Türkiye'de Bager Akbay tarafindan yaratılmış olan "Deniz Y1lmaz", 2 eksende hareket edebilen bir robot kola sahiptir. Bununla birlikte 12.000 şiirin data seti üzerinden Markov Zincirleri kullanılmıştır. Akbay'ın kullandığı makine öğrenmesi yöntemi ile Deniz Yılmaz'ın şiirlerinde kelime, uyak, hece ölçüsü dizilişleri gelişimini sürdürmüş, şiirleri mantıklı ve anlaşılır bir şekilde gelişmeye başlamıştır (Şekil 6). Bu gelişmelerle birlikte Deniz Yılmaz'ın ürettiği şiirlerin bir bütün haline gelebilmesi için “Diğerleri Gibi” adlı şiir kitabı çıkarılmıştır (Ballı, 2020).

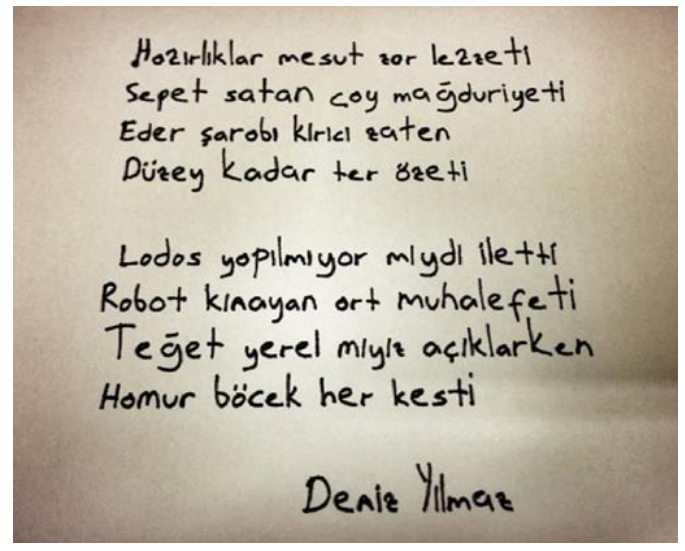

Şekil 6. Deniz Yılmaz tarafından yazılan şiir örneği (Ballı, 2020)

\section{Yapay Zeka'nın Ürettiği Çalışmalar Sanat Eseri Sayılır Mı?}

Toplumun bilim ve sanattan beklentileri farklılık gösterdiği gibi ortaya koymuş oldukları sonuçlara ve ürünlere gösterdikleri tepkilerde de farklılıklar görülmektedir (Dikmen, 2012). Geliştirilen her çalışma ile beraber yeni tartışma konuları olan etik, taklit ve sahiplik kavramları da dile gelmiştir.

İlk olarak belirtilebilir ki; bir yapay zekanın temelinde insan müdahalesi bulunmaktadır, ancak yapay zekanın ürettiği tüm sonuçların, insan müdahalesi ile elde edildiğini söyleyemeyiz. Tabi bununla beraber gelişen teknolojide halen insan müdahalesinin hiç olmadığı bir yapay zekâ sisteminden bahsetmek de güçtür. Nitekim algoritmalarla çalışan bilgisayarlara verilen girdi ile çıktı arasındaki bağın matematiksel kesinlikte olduğunu biliyoruz. Bu nedenle yapay zekaya resim çizmesi ya da şiir yazması öğretildiğinde onun geliştiriciye ne gibi bir çıktı vereceğini önceden tahmin etmesinin kesin bir imkânı yoktur.

"Yapay zekanın ürettiği ürünler bir eser sayılmalı mıdır?" sorusunun cevabında hukuk politikalarında yapılacak tercihlere de bağlıdır. Örneğin Amerikan Telif Hakları Ofisi Uygulamalarının 306. Paragrafının birinci cümlesinde insan müdahalesi olmadan yapay zekanın meydana getirdiği ürünlerin eser olarak kabul edilemeyeceği açıkça belirtilmiştir. Diğer taraftan İngiliz Telif Hakkı, Tasarımlar ve Patentler Kanunu'na bakacak olursak bu kanunun 178. maddesine göre bilgisayar tarafından üretilmiş eser tanımı yapılmıştır (Gözübüyük, 2021).
Tahmin edildiği üzere makine üretiminin, insan eserinin önüne geçemeyeceğini, yapay zekanın yarattığı çalışmaların sanat eseri sayılamayacağını savunan sanatçı ve sanat tarihçileri vardır. $\mathrm{Bu}$ savunmanın en başında Marcel Duchamp, Andy Warhol ve Eduard Manet gelmektedir. Böyle düşünmelerine neden olan şey sanatın tanımlarının ve yaratımının sanatçıya ait olduğu görüşüdür. Çünkü sanat manevi bir anlayış ve düşüncelerle biçimlenen sosyal bir gerçekliktir. Bir duyguyu, tasarıyı ya da bir güzelliği; renk, ses, 1şık, hatta zaman ve mekân ilişkisi kurarak, yeni yaratımlarla ortaya çıkaran üstün bir beceridir (Soysaldı, 2018).

\section{Sonuçlar}

Bilim ve sanat arasındaki ilişkiyi Arnold Hauser şu sözlerle açıklamaktadır: Sanat ne bilim olarak doğar ne de bilime dönüşerek son bulur. Sanat, yalnızca yaşamın zorluklarından doğar ve insan varoluşuyla yönlenen sonsuz yolda bilimle birlikte ilerler. Temelinde bilim olan teknoloji de hem sanatçının yaratıcı gücünün hem de halkın evrene, yeryüzüne yaklaşımının artırılmasına yönelik olarak sanat ile birleşmektedir (Yıldırım, 2018).

Bir taraftan yeni şeyler içerisinde bulunma isteği, diğer taraftan ise bu yeniliğin toplum üzerinde bıraktığı olumsuzlukları hissetmek insana özgü bir durumdur. Ancak teknolojinin geldiği son noktada ve gelecekte olabilecekler düşünüldüğünde; kaçınılmaz olarak insan-makine ilişkisi sanat alanında yapılan teknolojik yeniliklerle birlikte daha da gelişecektir. Bugün üretilen çalışmalara bakıldığında teknolojinin sunduğu yenilikler ve deneyimler sayesinde farklı disiplinler bir arada kullanılmaktadır. Geniş bir alana sahip olan yapay zekâ çalışmaları 21. yüzyılın sanat anlayışını etkilemiş, yeni bir anlatı oluşturmuş ve farklı görünümlerle hayatımıza girmiştir (Toprak, 2020).

Sonuç olarak yapay zekâ tarafından üretilen sanat, bilimsel araştırmalar sonucunda elde edilen bilgiler ile sanatsal çalışmalar kültür endüstrisine dönüşmüştür. Yapay zekâ ve sanat genel olarak yaşama, uygarlıkların düşünce dünyasının gelişmesine ve özelde eleştirel teorilere, kültürel teorilere ve sanatsal yaratıya kazandırılacak yeni bakış açılarıyla yaklaşmayı gerektirmektedir.

\section{Kaynakça}

Akbulut, D. (2020). Sanatın Ölümü Üzerine: Yanlış Cenazeye Ağıt, , Karadeniz Uluslararası Bilimsel Dergi , 1 (47), 91-107

Artut, S. (2019). Yapay Zekâ Olgusunun Güncel Sanat Çalışmalarındaki Açılımları, İnsan ve İnsan , 6 (22), 767-783

Aslan, E. (2019). Yapay Zekâ Resimleri Ve Sanatın Başkalaşan Mecrası Üzerine, Güzel Sanatlar Enstitüsü Dergisi, 231-242

AICAN, Erişim adresi: https://its-interesting.com/tag/ahmedelgammal/

Ballı, Ö. (2020). Yapay Zekâ Ve Sanat Uygulamaları Üzerine Güncel Bir Değerlendirme, Sanat ve Tasarım Dergisi

Dijital Baskı, Erişim adresi: https://deepdreamgenerator.com/

Dikmen, B. (2012). Değişen Dünyada Kültür, Sanat Ve Bilim İlişkisi, Batman Üniversitesi Yaşam Bilimleri Dergisi , 1 (1) , 137-144

Gözübüyük, B. (2021). Yapay Zekanın Meydana Getirdiği Fikri Ürünlere İlişskin 5846 Sayılı Fikir Ve Sanat Eserleri 
Kanunundaki Sorunlar Ve Çözüm Önerileri, KHM, 1(1), 54-81

Kozlu, D. (2009). Teknolojik Gelişmelerin Toplum Ve Sanata Yansımaları, Art-e Sanat Dergisi 2, 1-14

Mazzone, M. \& Elgammal, A. (2019). Art, Creativity and The Potential of Artificial Intelligence, Arts, 8(1), 26

Soysaldı, A. (2018). Kültür, Sanat Ve Beşeriyet İlişkisi, Sanat ve Tasarım Dergisi, 305-315

Resim 1, Erişim adresi:

https://www.ntv.com.tr/galeri/sanat/robot-sophianinyaptigi-tablo-688-bin-888-dolara-
satildi,5tGiNdkuVEGqzfLBPHnrGA/4H_oLkkW5UOF j8h5HPszvw

Toprak, A. (2020). Yapay Zekâ Algoritmalarının Dijital Enstalasyona Dönüşmesi, Ege Üniversitesi İletişim Fakültesi Yeni Düşünceler Hakemli E-Dergisi, 47-59

Ünal, E. (2018). Yapay Zekadan Sanatçıya, Tübitak Bilim Ve Teknik Dergisi, s:58-66.

Yildırım, M. (2019). Dijital Sanat ve Kolaj, Ekev Akademi Dergisi, 23(80), 319-338 